\title{
Expectations of Multiple Sclerosis Patients and Their Families: A Qualitative Study in Iran
}

\author{
Shahla Abolhassani ${ }^{1}$; Ahmadreza Yazdannik ${ }^{2, *}$; Fariba Taleghani ${ }^{3}$; Ahmadreza Zamani ${ }^{4}$ \\ ${ }_{2}^{1}$ Faculty of Nursing and Midwifery, Isfahan University of Medical Sciences, Isfahan, IR Iran \\ ${ }_{3}^{2}$ Critical Care Nursing Department, Faculty of Nursing and Midwifery, Isfahan University of Medical Sciences, Isfahan, IR Iran \\ ${ }^{3}$ Adult Health Nursing Department, Nursing and Midwifery Care Research Center, Faculty of Nursing and Midwifery, Isfahan University of Medical Sciences, Isfahan, IR Iran \\ ${ }^{4}$ Community and Family Medicine Department, Faculty of Medicine, Isfahan University of Medical Sciences, Isfahan, IR Iran \\ *Corresponding Author: Ahmadreza Yazdannik, Critical Care Nursing Department, Faculty of Nursing and Midwifery, Isfahan University of Medical Sciences, Isfahan, IR Iran. Tel: \\ +98-9133108878, E-mail:yazdannik@nm.mui.ac.ir
}

Received: February 17, 2014; Revised: April 26, 2014; Accepted: May 7, 2014

\begin{abstract}
Background: Multiple Sclerosis(MS) is a neurological disease that is most commonly observed among young people. Drug and non-drug treatments are used to prevent the progression of the disease and to control illness-related disorders. Patients with MS often have multiple and complicated needs that require a broad spectrum of health services.

Objectives: This study was conducted to identify the expectations of individuals with MS and their families for healthcare services.

Patients and Methods: This article is part of a qualitative case study. The participants were selected by a purposive sampling method. In this study, semi-structured interviews of 20 individuals with MS and 8 family members were conducted to identify the expectations of MS patients and their families. In addition to the interviews, the documents related to the aim of the study, including weblogs, MS magazines, special websites of individuals with MS, and news agencies were gathered. Analysis of data was performed by a conventional content analysis method.

Results: The age of the participants ranged from 22-63 years. The data obtained from this study was classified into 5 main categories as follows: being cured, need for comfort, promoting knowledge, economic welfare, and social security.

Conclusions:Individuals with MS and their families had different expectations pertaining to all dimensions of life, such that not meeting the needs related to any dimension could have affect the other dimensions. Therefore, it is necessary for healthcare providers to have a holistic assessment as well as try to meet all needs and expectations.
\end{abstract}

Keywords:Family; Multiple Sclerosis; Patients; Qualitative Research

\section{Background}

Multiple sclerosis (MS), a chronic disorder, is the most common neurological disease among young people (1). The estimated average global prevalence rate of this disease is 30 per 100,000 individuals with an even higher average rate in Europe (80 per 100,000 individuals) (2). The prevalence of MS has been estimated to be 51.9 from 2002-2008 in Tehran (3), 43.8 during 2003-2006 (4), and 73.3 per 100,000 individuals during 2003-2010 in Isfahan (5). MS is often diagnosed between the ages 20 and 40. The common symptoms of the disease include fatigue, intestinal and urinary disorders, visual problems, spasticity, swallowing, sexual, cognitive, and motor problems, depression, and pain (6). The quality of life of afflicted individuals is often reduced following the appearance of the above symptoms (7-9). Drug and non-drug treatments are used for the management and prevention of disease progression and for controlling illness-related disorders (10). In MS, managing the disease requires the help of different personnel with varying healthcare expertise to meet the needs of patients during their lifetime $(1,11)$. Since MS often occurs at a young age, the patients need long-term care. With the progression of the disease, pa- tient capacity to take care of themselves is reduced (12). Therefore, the burden of responsibility for patient care is transferred to the family (13). The economic effects of the disease arise from a loss of patient ability to work, hospitalization, the requirements to be helped to perform routine daily activities, and the direct costs resulting from the consumption of expensive drugs $(14,15)$. Considering the multiple effects of MS on the patients, their families, and society, it is necessary that the healthcare services offered to patients and families be effective and based on need (16). However, there is evidence that the needs of patients have not been met and that they are not satisfied with the services provided $(17,18)$. Studies employing quantitative methods were performed to assess the needs and available services for patients with neurological disorders, through the use of questionnaires $(16,19-21)$ or qualitative methods of interviewing patients $(22,23)$.

\section{Objectives}

The present study was conducted with the aim of identifying the expectations of MS patients and their families for healthcare services, with a qualitative method. This

Copyright (C) 2015, Iranian Red Crescent Medical Journal. This is an open-access article distributed under the terms of the Creative Commons Attribution-NonCommercial 4.0 International License (http://creativecommons.org/licenses/by-nc/4.0/) which permits copy and redistribute the material just in noncommercial usages, provided the original work is properly cited. 
information would, in turn, assist in providing better services. This study is of importance, given the expectations of MS patients regarding social, psychological, and cultural factors, of identifying the needs and expectations of these service users to provide proper healthcare services and the lack of previous research on the needs of MS patients in Iran.

\section{Patients and Methods}

This article is a part of a qualitative case study that served as a PhD dissertation. The study focused on the disease experience, expectations, and health services delivered to MS patients and their families. This study was conducted at the MS Association and two hospitals in Isfahan, Iran, which have MS clinics and neurology wards. The data were collected from January 2012 to April 2013. The participants in this study included individuals with MS and family caregivers. The general eligibility criteria for the participants were as follows: a willingness to participate in the study, the ability to take part in the interview and communicate experiences, and a confirmed diagnosis of MS by the neurologist. The participants meeting the eligibility criteria were selected using a purposive sampling method with maximum variation from MS clinics and neurology units of teaching hospitals of Isfahan University of Medical Sciences and Isfahan MS Association. Participants who represent a maximum variation based on gender, age, marital, educational, employment, and income status were invited. Semi-structured, face-to-face interviews with the participants were conducted at the MS Clinic, participant homes, and Isfahan MS Association as per the participant's choice. At the beginning of the interview, the participants were requested to explain their illness and then their expectations. To provide a sample of the questions, they were asked to explain their illness, what their opinion of available services was, and what their expectations from the services for them and their families were. The average duration of the interviews was $58 \mathrm{~min}$, with a range of 20-120 min. The interviews were continued until no new data was obtained. Data was saturated after conducting interviews with 28 participants. The approval to conduct the study was granted by the Ethics Committee of the Isfahan University of Medical Sciences (Code of ethical approval was 3904050). The research investigator introduced herself to the participants and explained the objectives of the study. The participants were assured that confidentiality, anonymity will be maintained, and they were free to not participate at any step of the study. Written informed consent was obtained from all the participants. The researcher also collected documents related to the objective of the study, including weblogs of MS patients, materials from news agencies, and special conservation issues of site members of the MS Center and bimonthly MS magazine. Weblogs did not belong to patients in this study. Criteria for choosing weblogs were having experiences of patients and their expectations. The data obtained from these interviews and documents was analyzed by conventional qualita- tive content analysis, which is a systematic approach for data coding and categorizing (24). This approach helps in avoiding the use of preconceived categories and allows the categories to emerge from the data(25). The interviews were transcribed word by word, read accurately several times, and open-coded. For open coding, the interviews were divided into semantic units that were summarized in the next step and converted into codes. Codes were compared based on their differences and similarities, and similar codes were grouped into subcategories. In the next step, subcategories were compared with each other, and similar categories were combined in a manner that the main categories finally emerged. Criteria such as credibility, transferability, confirmation, and dependability were used by the researcher to verify trustworthiness. Longterm engagement, feedback from participants, and peer verification were employed to increase the credibility of the study. The researcher conducted interviews and repetitive meetings with the participants for an in-depth understanding of each participant could be achieved. Moreover, feedback was obtained from each participant to verify the codes and interpretations made based on each interview. The codes resulting from the data were also verified by the researcher's colleagues to survey peer understanding. The researcher's colleagues were presented with the data to investigate the accuracy of its analysis process. All crude data such as recorded tapes and documentations were maintained by the researcher. To increase transferability, the researcher proceeded to describe the study process and conducted activities in a precise and objective-oriented manner.

\section{Results}

Twenty-eight individuals participated in this study, including 20 individuals with MS and 8 family members. The age of the participants ranged between 22 and 63 years, $21 \%$ were male and $17 \%$ were single. Tables 1 and 2 show the demographic characteristics of the participants. The data obtained from this study was categorized into 5 main categories as follows: being cured, need for comfort, promoting knowledge, economic welfare, and social security (Table 3 ).

\subsection{Getting Cured}

After experiencing different symptoms and several periods of relapse, some of the participants expected the illness symptoms to be eliminated. Some of the participants were tired of long-term treatments and wanted to be rid of them by any means to be able to resume a normal life. Due to tiredness because of treatments, some patients had interrupted their drug treatments in the hope of improvement. Instead, they had followed treatments such as bee or herbal therapies with the expectation that a treatment intervention would result in a complete cure. "I think that if a very effective drug is presented, even if its price is high but it cures the patients, it is very good" (P5). 
Abolhassani S et al.

\begin{tabular}{|c|c|c|c|c|c|c|c|}
\hline ID Code & Age, $y$ & Gender & $\begin{array}{l}\text { Marital } \\
\text { Status }\end{array}$ & Job & Education & Disease Type & $\begin{array}{l}\text { Years of } \\
\text { Disease }\end{array}$ \\
\hline P1 & 38 & Female & Married & Housekeeper & diploma & Secondary progressive & 12 years \\
\hline P2 & 22 & Male & Single & Unemployed & Diploma & Relapsing remitting & 4 years \\
\hline P3 & 27 & Female & Married & House keeper & Junior high school & Relapsing remitting & 7 years \\
\hline P4 & 37 & Female & Single & Employee & BS & Secondary progressive & 7 years \\
\hline P5 & 35 & Female & Married & Housekeeper & primary & Relapsing remitting & 8 years \\
\hline P6 & 39 & Female & Married & Housekeeper & primary & Relapsing remitting & 5 years \\
\hline P7 & 27 & Male & Single & Unemployed & BS & Relapsing remitting & 5 years \\
\hline P8 & 25 & Female & Married & Housekeeper & BS & Relapsing remitting & 6 month \\
\hline P9 & 40 & Female & Married & Housekeeper & primary & Relapsing remitting & 6 years \\
\hline P10 & 38 & Female & Married & House keeper & diploma & Secondary progressive & 15 years \\
\hline P11 & 29 & Female & Married & Advocacy trainee & BS & Relapsing remitting & 7 years \\
\hline P12 & 40 & Male & Married & Manager & BS & $\begin{array}{l}\text { Secondary progressive, } \\
\text { wheelchair bound }\end{array}$ & 17 years \\
\hline P13 & 46 & Male & Married & Teacher & BS & Relapsing remitting & 3 years \\
\hline P14 & 43 & Female & Married & Housekeeper & diploma & Secondary progressive & 20 years \\
\hline P15 & 30 & Female & Single & Employee & BS & Relapsing remitting & 15 years \\
\hline P16 & 27 & Female & Married & Housekeeper & Senior high school & Relapsing remitting & 1 years \\
\hline P17 & 39 & Female & Married & Housekeeper & diploma & Relapsing remitting & 4 years \\
\hline P18 & 23 & Female & Married & Student & BS student & Relapsing remitting & 4 years \\
\hline P19 & 29 & Female & Married & BS & House keeper & New case & $\begin{array}{c}2 \text { weeks after } \\
\text { diagnosis }\end{array}$ \\
\hline P20 & 35 & Female & Married & BS & teacher & New case & $\begin{array}{l}\text { One week af- } \\
\text { ter diagnosis }\end{array}$ \\
\hline
\end{tabular}

\footnotetext{
a Abbreviation: P, patient.
}

Table 2. Demographic Characteristics of Family Members a

\begin{tabular}{|c|c|c|c|c|c|c|c|c|c|c|}
\hline ID Code & Age, $y$ & Gender & $\begin{array}{c}\text { Marital } \\
\text { status }\end{array}$ & Job & $\begin{array}{l}\text { Educa- } \\
\text { tion }\end{array}$ & $\begin{array}{c}\text { Relation With } \\
\text { Individual } \\
\text { With MS }\end{array}$ & $\begin{array}{c}\text { Age of } \\
\text { Individual } \\
\text { With MS }\end{array}$ & $\begin{array}{c}\text { Sex of } \\
\text { Individual } \\
\text { With MS }\end{array}$ & $\begin{array}{c}\text { Disease Type } \\
\text { of Individual } \\
\text { With MS }\end{array}$ & $\begin{array}{l}\text { Years of } \\
\text { Disease }\end{array}$ \\
\hline F1 & 36 & Female & Married & Employee & BS & Wife & 40 & Male & $\begin{array}{c}\text { Progressive, } \\
\text { wheelchair } \\
\text { bound }\end{array}$ & 17 years \\
\hline F2 & 41 & Female & Married & Teacher & BS & Wife & 46 & Male & $\begin{array}{l}\text { Relapsing } \\
\text { Remitting }\end{array}$ & 3 years \\
\hline F3 & 63 & Female & Married & Housekeeper & Primary & Mother & 36 & Female & $\begin{array}{l}\text { Progressive, } \\
\text { bed ridden }\end{array}$ & 14 years \\
\hline F4 & 52 & Female & Married & Teacher & BS & Mother & 30 & Female & $\begin{array}{l}\text { Relapsing } \\
\text { remitting }\end{array}$ & 15 years \\
\hline F5 & 23 & Female & single & Student & $\begin{array}{l}\text { BS stu- } \\
\text { dent }\end{array}$ & Daughter & 43 & Female & $\begin{array}{l}\text { Progressive, } \\
\text { bed ridden }\end{array}$ & 18 years \\
\hline F6 & 39 & Male & Married & Seller & Primary & Husband & 32 & Female & $\begin{array}{l}\text { Relapsing } \\
\text { remitting }\end{array}$ & 1 years \\
\hline F7 & 47 & Male & Married & Seller & Diploma & Husband & 39 & Female & Progressive & 21 years \\
\hline F8 & 42 & Female & married & $\begin{array}{l}\text { School ser- } \\
\text { vice driver }\end{array}$ & Diploma & Wife & 47 & Male & Progressive & 6 years \\
\hline
\end{tabular}

a Abbreviation: $\mathrm{F}$, family member. 
Abolhassani S et al.

\begin{tabular}{|c|c|}
\hline Subcategory & Participant Percent, \% \\
\hline \multicolumn{2}{|l|}{ Getting cured } \\
\hline Complete treatment & 42.86 \\
\hline Fast removing & 35.71 \\
\hline \multicolumn{2}{|l|}{ Need for Comfort } \\
\hline Comfort for patient & 82.14 \\
\hline $\begin{array}{l}\text { Comfort for family mem- } \\
\text { bers }\end{array}$ & 35.71 \\
\hline \multicolumn{2}{|l|}{ Promoting knowledge } \\
\hline $\begin{array}{l}\text { Education for individual } \\
\text { with Multiple sclerosis }\end{array}$ & 57.14 \\
\hline $\begin{array}{l}\text { Education for family } \\
\text { members }\end{array}$ & 39.28 \\
\hline \multicolumn{2}{|l|}{ Economic welfare } \\
\hline Reducing treatment costs & 64.28 \\
\hline Support from organizations & 53.57 \\
\hline \multicolumn{2}{|l|}{ Social security } \\
\hline Strategies for stigma & 60.71 \\
\hline Career support & 28.57 \\
\hline Urban optimization & 21.42 \\
\hline
\end{tabular}

Some of the participants expected swift elimination of the symptoms, which were of annoyance to them; otherwise, they referred back to their physician or even changed their physician to obtain the intended result.

"He expects to be cured very soon, he expects a drug that, if taken tonight, will cure him by tomorrow" (F2).

\subsection{Need for Comfort}

Some of the participants of this study expected that the patient and family would receive comfort because of the psychological burden associated with illness. One of the expectations of MS patients was a need for attention and sympathy. They expected healthcare personnel to consider their needs and sympathize with them. Some participants even decided to change their physician due to the lack of attention to their needs, and instead, choose a physician who is sympathetic to their needs. "I still had not finished talking, when he/she gave me his/her prescription. I expected the physician to listen to me and get to know my problems; when he/she wrote down the prescription, I thought, what is its use?" (P1).

Individuals with MS expected healthcare personnel to consider their human spirit and not behave with them or their families in a way that made them feel weak. The participants also expected consideration of the psychological aspects of their illness from diagnosis to progression, and recognized that they needed psychological support not only during diagnosis but also throughout the course of their illness. In addition, the families of bedridden MS patients with advanced illness expected healthcare pro- viders to appease the patient and not be left alone. They also expected personnel to follow-up on the condition of the patient and their families. "We expected them to call in, because that would make the patient happy; if the patient would like to go on vacation, they must know, as it is important to ask the patient to go with them" (F3).

The families of MS patients who were experiencing the psychological burden associated with the patients' illness also expected psychological support. They expected that they would be offered an opportunity to relieve their emotions, which could reduce their psychological pressure, helping them care better for the patients. "Now I am very comfortable, my morale has improved (by speaking with the researcher). You spoke with me because I was very unhappy; such consultation is good for those of us" (F4).

In addition to tolerating the psychological burden associated with the illness, some of family members were confused regarding the manner of dealing with the patient and expected guidance from a knowledgeable person.

\subsection{Promoting Knowledge}

The participants noted that they had to be instructed to obtain more information about the illness and comply better with it. Additionally, enhancing the knowledge and awareness of people around the MS patient was also expected to improve familial relationships. One of the problems faced by some MS patients was that the diagnosis was concealed from them by the attending physician. For others, the diagnosis was raised in an ambiguous manner such that the patient experienced fear and worry because of the lack of proper knowledge. The participants expected their physicians to tell them the diagnosis and provide them with suitable information regarding the course of MS and treatment trends during all steps of the illness to prevent the patient from developing an erroneous expectation of rapid recovery. "Unfortunately, this explanation is such that nobody understands it. We do not know anything; we are confused about what it is, what my situation is. If I know that it would last for 10 days, I will tolerate it for 10 days" (P13).

The participants also placed emphasis on the importance of educating their families about the illness and its effects on the patient. They felt that this resulted in better compliance of the family with the patients' problems as well as proportional expectations based on the patients' condition. "If the male and female family members are educated separately with regard to the method of dealing with the patient, then they would understand the problems faced by individuals with MS" (P14).

\subsection{Economic Welfare}

Some of the participants expected financial support because of their need for continuous treatment, various services, and certain expensive drugs, the financial effects of their illness on their job and income, and problems in meeting treatment costs. In addition, they expected 
some of the services to be provided free of charge, and expressed satisfaction with some of these. However, they expected the other services also to be provided free of charge or at least with reduced costs. The participants expected that they would be supported financially, because they experienced the psychological burden following economic problems. "I need this money very much; it is very difficult for us to provide the money" (P3).

Financial support was expected by some participants from organizations, including charity organizations. The participants hated the compassionate attitudes of other people towards them. Moreover, they did not like being helped in a way that hurt their self-respect. The families of individuals with progressive illness who faced monetary issues expected help from indirect sources, including relevant organizations, so that they could be supported in a manner that maintained their self-respect. "We just expect that they ask what the patient needs. I expect the MS association and State Welfare Organization to help me, because the patient is under their supervision" (F3).

\subsection{Social Security}

Individuals with MS and their families expected social support because they experienced social burden. This support included strategies for coping with stigma, job support, and urban optimization. Individuals with MS wanted the establishment of cultural awareness of MS because they experienced social stigma resulting from improper awareness of this illness among people and from their misbehavior. MS patients expected that people should be educated about MS, so that they understood the patients' condition instead of pitying them. The participants believed that the problems they faced with married life were also due to the misconceptions about MS in society. Thus, these problems could also be eliminated by disseminating correct information. They believed that mass media could be effective in this regard. "why are people still without any information about MS are very pessimistic, sufficient information about MS must be provided to the people" (a patient's weblog). Individuals with MS expected that they would receive support for acquiring jobs and that their employment would be prioritized because of their concerns about their careers. "We expect them to support us as MS patients. For example, a patient with mild MS, being currently unemployed. He/ she can work; if there is any job, they should give priority to MS patients" (P7).

Moreover, the employed participants were also afraid of losing their jobs. Thus, most of them had concealed their diagnosis in their working environment due to anxiety. The participants expected support in their working environments, understanding of their condition by the employers, and co-operation for receiving treatment during periods of illness relapse so that MS patients do not experience concern about losing their job. "I am always afraid of canceling the class and coming for treatment. This is the main reason for my stress. If I want to be absent for three days, they should temporarily assign another person" (P13).

The individuals with progressive MS and motor problems expected such civic amenities and facilities, which would enable their presence in society in a comfortable manner, without confronting problems in performing their personal affairs. "I'm riding the bus or subway a lot, and when I ride if there is no place to sit, get in the middle, I do not have the strength to hold my hand tight, so now I am fall several times." (MS center website).

\section{Discussion}

Being cured was one of the expectations of the participants. Given the progression of the illness despite therapy and occurrence of periods of relapse, they expected that a complete treatment would be found. They were tired of continuing therapy that lacked any benefits. Similarly, Daugherty indicated the reasons for interrupting interferon therapy included progression of the illness and the patients' understanding of the ineffectiveness of the drug (26). Some of the participants in the current study expected very rapid elimination of the annoying symptoms of the illness and changed their physician because of the ineffectiveness of the therapy. In another study, Forbes showed that patients expected treatment of the illness and control of its symptoms and progression (21). Another expectation of the participants pertained to the comfort of individuals with MS and their families. The participants expected others to sympathize with them and continuously offer psychological support throughout the course of their illness. Vazirinejad showed that the psychological dimension was the most important one governing the quality of life for patients with mild to severe MS (27). Moreover, the MS patients examined by Gottberg expected that they would be offered consultation services (19). The participants in the current study also experienced psychological problems and expected healthcare providers to pay attention to their psychological needs. In addition to the individuals with MS, their families also expected psychological support to reduce their psychological burden and help them care better for the patients. The family members expected that they would be consulted regarding the manner of dealing with the patient. Egger indicated that $30 \%$ of family caregivers noted the need for receiving consultation to help them manage their feelings related to illness burden better (28). Moreover, Koopman indicated that the psychological needs of caregivers were considered their most important needs and they needed to be heard and have access to appropriate support (29). Similarly, participants of the current study also needed psychological support from healthcare providers. Another expectation of the participants was that the patients and their families should be instructed about the illness, treatment trends, and illness-related problems. In Forbes (21) and Courts (30), the participants raised the need for providing information about MS to the family members for amending 
the family members' understanding of MS and the influence of the illness on the patient. Economic support was another of the expectations of the participants in the current study. Because they experienced financial burden due to illness, they expected a reduction in the cost of treatment or the provision of services free of charge. This is similar to Forbes, where the issues of funding the interferon treatment and financial help were raised by the patients (20). Koopman revealed that financial security was raised as an important requirement by the patients (29). Along these lines, the participants in the current study expected charity organizations to help them, so that their self-respect was maintained. Social support was yet another expectation of the participants of the current study. The experience of stigma by the participants led to their expectation that the strategies to cope with stigma would also be offered by society. They expected that the attitudes of people in society regarding MS would be changed by providing proper information. The participants believed that the mass media must portray different layers of the lives of MS patients and that the producers of programs should consult with experts to provide suitable information about MS. In Zoller, the individuals with MS expected a true picture of MS is conveyed to the people (31). Because the participants faced problems related to occupation, they requested that hiring of MS patients should be prioritized. Sweetland indicated that patients required support in their working environment, and accordingly, had expectations from their employers (20). Moreover, Dyck showed that although the disease symptoms influence the career situation of patients, non-medical factors such as understanding of the patients' condition by the employer and change in work conditions could prove effective (32). The participants of the current study also expected that suitable facilities for their transportation and other necessities should be provided. This is consistent with studies by Gottberg (19), Forbes (21), and McCabe where individuals with MS and progressive neurologic disorders expected that suitable transportation services would be provided for them, enabling their presence in society. The strength of the current study is the collection of data from different sources to obtain deeper insight about the study subject. Another strength of the study is the emergence of potential suggests how to intervene to promote a more positive outcome for people with MS. This study examined a small sample of patients with MS and their families living in Iran. This issue might limit the generalizability of our results. Individuals with MS and their families have different needs and expect the healthcare providers to attend to their needs. Therefore, healthcare providers are required to make holistic assessment of all the needs of the patients and their family members as well as try to meet them. The absence of such holistic assessment while offering healthcare to MS patients and their families could possibly enhance the psychological burden of the patient or his/her family. Therefore, it is the responsibility of the healthcare service providers, policy makers, and social institutions to try to meet the needs of individuals with MS and their families.

\section{Acknowledgements}

The authors would like to thank the individuals with MS and their family members who participated in this study and Isfahan MS Clinics and MS Association.

\section{Authors' Contributions}

Study concept and design: Shahla Abolhassani, Ahmadreza Yazdannik, Fariba Taleghani Acquistion of data: Shahla Abolhassani Analysis and Interpretation of data: Shahla Abolhassani, Ahmadreza Yazdannik, Fariba Taleghani Drafting of the manuscript:Shahla Abolhassani Critical revision of the manuscript for important intellectual content: Ahmadreza Yazdannik, Fariba Taleghani, Ahmadreza Zamani Study Supervision: Ahmadreza Yazdannik, Fariba Taleghani, Ahmadreza Zamani.

\section{Funding/Support}

This work was supported by the Isfahan University of Medical Sciences.

\section{References}

1. Barker EM. Neuroscience nursing. 3rd edSt. Louis: Mosby Elsevier; 2008.

2. World health organization.. Atlas: Multiple Sclerosis Resources in the World 2008. 2008. Available from: http://www.who.int/ mental_health/neurology/atlas_multiple_sclerosis_resources_2008/en/.

3. Sahraian MA, Khorramnia S, Ebrahim MM, Moinfar Z, Lotfi J, Pakdaman H. Multiple sclerosis in Iran: a demographic study of 8,000 patients and changes over time. Eur Neurol.2010;64(6):3316.

4. Etemadifar M, Janghorbani M, Shaygannejad V, Ashtari F. Prevalence of multiple sclerosis in Isfahan, Iran. Neuroepidemiology. 2006;27(1):39-44.

5. Etemadifar M, Maghzi AH. Sharp increase in the incidence and prevalence of multiple sclerosis in Isfahan, Iran. Mult Scler 2011;17(8):1022-7.

6. Platform EM. Code of good practice in MS. platform. 2008.

7. Pakpour AH, Yekaninejad MS, Mohammadi NK, Molsted S, Zarei F, Patti F, et al. Health-related quality of life in Iranian patients with multiple sclerosis: a cross-cultural study. Neurol Neurochir Pol. 2009;43(6):517-26.

8. Aymerich M, Guillamon I, Jovell AJ. Health-related quality of life assessment in people with multiple sclerosis and their family caregivers. A multicenter study in Catalonia (Southern Europe). Patient Prefer Adherence. 2009;3:311-21.

9. Ghaem H, Borhani Haghighi A. The impact of disability, fatigue and sleep quality on the quality of life in multiple sclerosis. Ann Indian Acad Neurol. 2008;11(4):236-41.

10. Asche CV, Singer ME, Jhaveri M, Chung H, Miller A. All-cause health care utilization and costs associated with newly diagnosed multiple sclerosis in the United States. J Manag Care Pharm. 2010;16(9):703-12.

11. Wallin MT. Integrated multiple sclerosis care: new approaches and paradigm shifts. J Rehabil Res Dev. 2010;47(5):ix-xiv.

12. Buhse M. Assessment of caregiver burden in families of persons with multiple sclerosis. J Neurosci Nurs. 2008;40(1):25-31.

13. Arnett PA. Caregiver burden in multiple sclerosis. J Neurol Neurosurg Psychiatry. 2007;78(10):1041.

14. Jennum P, Wanscher B, Frederiksen J, Kjellberg J. The socioeco- 
nomic consequences of multiple sclerosis: a controlled national study. Eur Neuropsychopharmacol. 2012;22(1):36-43.

15. Rotstein Z, Hazan R, Barak Y, Achiron A. Perspectives in multiple sclerosis health care: special focus on the costs of multiple sclerosis. Autoimmun Rev. 2006;5(8):511-6.

16. Ytterberg C, Johansson S, Gottberg K, Holmqvist LW, von Koch L. Perceived needs and satisfaction with care in people with multiple sclerosis: a two-year prospective study. BMC Neurol. 2008;8:36.

17. Edmonds P, Vivat B, Burman R, Silber E, Higginson IJ. 'Fighting for everything': service experiences of people severely affected by multiple sclerosis. Mult Scler. 2007;13(5):660-7.

18. Pohar SL, Jones CA, Warren S, Turpin KV, Warren K. Health status and health care utilization of multiple sclerosis in Canada. Can J Neurol Sci. 2007;34(2):167-74.

19. Gottberg K, Einarsson U, Ytterberg C, Fredrikson S, von Koch L, Holmqvist LW. Use of health care services and satisfaction with care in people with multiple sclerosis in Stockholm County: a population-based study. Mult Scler. 2008;14(7):962-71.

20. Sweetland J, Riazi A, Cano SJ, Playford ED. Vocational rehabilitation services for people with multiple sclerosis: what patients want from clinicians and employers. Mult Scler. 2007;13(9):1183-9.

21. Forbes A, While A, Taylor M. What people with multiple sclerosis perceive to be important to meeting their needs. J Adv Nurs. 2007;58(1):11-22.

22. Hampton NZ, Zhu Y, Ordway A. Access to Health Services: Experiences of Women with Neurological Disabilities. J Rehabilitation. 2011;77(2):3-11.
23. McCabe MP, Roberts C, Firth L. Satisfaction with services among people with progressive neurological illnesses and their carers in Australia. Nurs Health Sci. 2008;10(3):209-15.

24. Grbich C. Qualitative data analysis: An introduction.: SAGE; 2012.

25. Hsieh HF, Shannon SE. Three approaches to qualitative content analysis. Qual Health Res. 2005;15(9):1277-88.

26. Daugherty KK, Butler JS, Mattingly M, Ryan M. Factors leading patients to discontinue multiple sclerosis therapies. J Am Pharm Assoc (2003). 2005;45(3):371-5.

27. Vazirinejad R, Lilley JM. Measuring perceived quality of life to assess health needs among people with MS: a community study in Derbyshire, UK. Iran J Public Health. 2008;37(3):29-35.

28. Egger B, Muller M, Bigler S, Spirig R. [Understanding needs of people with Multiple Sclerosis. Perspective of patients and significant others in the German-speaking part of Switzerland]. Pflege. 2012;25(5):329-41.

29. Koopman WJ, Benbow CL, Vandervoort M. Top 10 needs of people with multiple sclerosis and their significant others. J Neurosci Nurs. 2006;38(5):369-73.

30. Courts NF, Newton AN, McNeal LJ. Husbands and wives living with multiple sclerosis. J Neurosci Nurs. 2005;37(1):20-7.

31. Zoller HM, Worrell T. Television illness depictions, identity, and social experience: responses to multiple sclerosis on The West Wing among people with MS. Health Commun. 2006;20(1):69-79.

32. Dyck I, Jongbloed L. Women with multiple sclerosis and employment issues: a focus on social and institutional environments. Can J Occup Ther. 2000;67(5):337-46. 